\title{
Learning Transversal Competences in the Digital Society
}

\author{
Sandro Serpa \\ University of the Azores, Faculty of Social and Human Sciences, Department of Sociology; \\ Interdisciplinary Centre of Social Sciences - CICS.UAc/CICS.NOVA.UAc; \\ Interdisciplinary Centre for Childhood and Adolescence - NICA - UAc
}

\begin{abstract}
We are moving towards an increasingly digital society, where artificial intelligence and the virtual dimension are central to all societal and individual dimensions (social, economic and political). This is a new reality in which the learning of transversal skills will be central to successful social integration as well as to a reduction of existing inequalities. Based on a selection of the most relevant bibliography, we develop a perspective paper. This communication aims to discuss, mobilizing a reasoned argument, the importance and the way in which the learning of these transversal competences can be fostered, focusing on the school (more formal) and educational (broader) dimensions. It was concluded that the teaching-learning process needs to undergo a transformation towards learning based on a participatory research-action logic in which all stakeholders, while respecting the role of each one, assume an active centrality in their own learning. As implications, we highlight that this teaching-learning logic calls into question the traditional school culture that is widely shared at all levels of education, based on a large asymmetry between those who teach and those who learn, which is an extremely challenging factor for the school culture transformation that we believe is essential to be implemented.
\end{abstract}

Keywords: action-research participatory; digital society; learning processes, teaching transversal competencies; transversal competences 